\title{
Developmental Switch in Spike Timing-Dependent Plasticity at Layers $4-2 / 3$ in the Rodent Barrel Cortex
}

\author{
Chiaki Itami ${ }^{1}$ and Fumitaka Kimura ${ }^{2}$ \\ ${ }^{1}$ Department of Physiology, Faculty of Medicine, Saitama Medical University, Moroyama, Saitama 350-0495, Japan and ${ }^{2}$ Department of Molecular \\ Neuroscience, Osaka University Graduate School of Medicine Suita 565-0871, Japan
}

Sensory deprivation during the critical period induces long-lasting changes in cortical maps. In the rodent somatosensory cortex (S1), its precise initiation mechanism is not known, yet spike timing-dependent plasticity (STDP) at layer 4 (L4)-L2/3 synapses are thought to be crucial. Whisker stimulation causes "L4 followed by L2/3" cell firings, while acute single whisker deprivation suddenly reverses the sequential order in L4 and L2/3 neurons in the deprived column (Celikel et al., 2004). Reversed spike sequence then leads to long-term depression through an STDP mechanism (timing-dependent long-term depression), known as deprivation-induced suppression at L4-L2/3 synapses (Bender et al., 2006a), an important first step in the map reorganization. Here we show that STDP properties change dramatically on postnatal day 13-15 (P13-P15) in mice S1. Before P13, timing-dependent long-term potentiation ( $t$-LTP) was predominantly induced regardless of spiking order. The induction of t-LTP required postsynaptic influx of $\mathrm{Ca}^{2+}$, an activation of protein kinase A, but not calcium/calmodulin-dependent protein kinase II. Consistent with the strong bias toward t-LTP, whisker deprivation (all whiskers in Row "D") from P7-P12 failed to induce synaptic depression at L4-L2/3 synapses in the deprived column, but clear depression was seen if deprivation occurred after P14. Random activation of L4, L2/3 cells, as may occur in response to whisker stimulation before P13 during network formation, led to potentiation under the immature STDP rule, as predicted from the bias toward t-LTP regardless of spiking order. These findings describe a developmental switch in the STDP rule that may underlie the transition from synapse formation to circuit reorganization at L4-L2/3 synapses, both in distinct activity-dependent manners.

\section{Introduction}

Mammalian sensory cortex shows remarkable plasticity during the critical period, in which deprivation of sensory input induces long-lasting changes in the visual (Wiesel and Hubel, 1963; Gordon and Stryker, 1996) and barrel cortices (Glazewski and Fox, 1996; Finnerty et al., 1999; Allen et al., 2003; Celikel et al., 2004). To understand its precise synaptic mechanism responsible for such plastic changes has certainly been one of the major goals of this field.

Spike timing-dependent plasticity (STDP) has emerged as a candidate mechanism for experience-dependent changes in the neural circuit, including map plasticity (Dan and Poo, 2006; Feldman, 2009). Whisker stimulation causes sequential "L4 followed by L2/3" firing in the rodent barrel cortex (Simons, 1978; Armstrong-James et al., 1992; Armstrong-James, 1995; Brumberg et al., 1999; Celikel et al., 2004), which, under STDP, leads to

Received May 24, 2012; revised Aug. 21, 2012; accepted Aug. 27, 2012.

Author contributions: C.I. and F.K. designed research; C.I. and F.K. performed research; C.I. and F.K. analyzed data; C.I. and F.K. wrote the paper.

This work was supported by a Grant-in-Aid for Scientific Research on Innovative Areas "Mesoscopic Neurocircuitry" (\#23115515) and \#20500358 (F.K.) and \#19700293 (C.I.) of The Ministry of Education, Science, Sports, and Culture of Japan.

The authors declare no competing financial interest.

Correspondence should be addressed to Fumitaka Kimura, Department of Molecular Neuroscience, Osaka University Graduate School of Medicine, Suita 565-0871, Japan, E-mail: fkimura@nphys.med.osaka-u.ac.jp; or Chiaki Itami, Department of Physiology, Saitama Medical University, Moroyama, Saitama 350-0495, Japan. E-mail: chiaki@saitama-med.ac.jp.

DOI:10.1523/JNEUROSCI.2506-12.2012

Copyright $\odot 2012$ the authors $\quad 0270-6474 / 12 / 3215000-12 \$ 15.00 / 0$ a strengthening of these synapses (Feldman, 2000). Trimming or plucking a subset of whiskers, however, suddenly reverses the spike sequences in the deprived column. The resultant " $\mathrm{L} 2 / 3$ followed by L4" firings cause depression at L4-L2/3 transmission following the timing-dependent long-term depression (t-LTD) mechanism (Allen et al., 2003; Celikel et al., 2004; Bender et al., 2006a). Subsequently, L2/3 cells in the deprived column would slowly, but increasingly, become innervated by adjacent columns. In this manner, rapid depression in the deprived column and slow potentiation from adjacent columns are thought to underlie map reorganization (Fox, 1992; Diamond et al., 1993; Glazewski and Fox, 1996). This predicts that if it is difficult to induce LTD, then sensory deprivation may fail to lead map reorganization because of insufficient deprivation-induced suppression. This idea is consistent with the recent finding that endocannabinoid signaling, which underlies timing-dependent LTD, is required for critical period plasticity (Li et al., 2009). Recently, while investigating the development of the property of L4 fast spiking (FS) GABAergic neurons, we found a possibility that "L4 followed by L2/3" whisker responses are established only after P12-P14 (Kimura et al., 2010). In fact, previous studies revealed that P12-P14 is the time when plasticity begins (Stern et al., 2001) or is most robust throughout life, although it persists substantially in adulthood. Thus spiking precision and response reliability are rapidly improved during this period, which was revealed by depriving all the whiskers but one (Clem et al., 2008; Benedetti et al., 2009; Wen and Barth, 2011), as well as by a developmental study from intact animals (Stern et al., 2001), with 
simultaneous recording from multiple sites (Ikezoe et al., 2012). These raised the question of whether the properties of STDP change during development, in particular during the P12-P14 period. Here we found that STDP is strongly developmentally regulated, with a profound bias toward LTP before P13, and standard STDP with LTD is seen only after P15. Consistent with these findings, whisker deprivation in vivo during the second postnatal week (P7 to P12-P14) failed to weaken L4-L2/3 synaptic transmission as measured by field potentials in ex vivo S1 slices. Instead, immature STDP may help form synaptic connections under nonsequential whisker responses in L4-L2/3 cells, because even random firing of presynaptic and postsynaptic cells could lead to strengthening under an immature STDP rule. Thus, we describe a developmental switch in the STDP rule that potentially plays distinct roles in the development and plasticity in the cortical network.

\section{Materials and Methods}

The experimental protocol used in this study was approved by the Animal Research Committee of Saitama Medical School and the Animal Experiment Committee of Osaka University Graduate School of Medicine.

Slice preparation. Thalamocortical slices $(350-400 \mu \mathrm{m})$ were prepared from C57BL/6J mice of both sexes on P7-P21 using a rotor slicer as described previously (Agmon and Connors, 1991; Itami et al., 2001, 2007). Mice were deeply anesthetized with isoflurane (Escain, $>2 \%$, inhalation; Mylan) and decapitated. Each brain was rapidly sliced in icecold artificial CSF (ACSF) composed of the following (in mM): $124 \mathrm{NaCl}$, $3 \mathrm{KCl}, 1.2 \mathrm{NaH}_{2} \mathrm{PO}_{4}, 1.3 \mathrm{MgSO}_{4}, 2 \mathrm{CaCl}_{2}, 10$ glucose, and $26 \mathrm{NaHCO}_{3}$, bubbled with $95 \% \mathrm{O}_{2}-5 \% \mathrm{CO}_{2}$, and balanced at $\mathrm{pH} 7.4$ (295-305 $\mathrm{mOsm}$ ). Slices were then immediately transferred to a holding chamber, where they remained submerged in oxygenated ACSF for at least $1 \mathrm{~h}$ before being transferred to a recording chamber on the stage of an upright microscope. The temperature was maintained at $27-30^{\circ} \mathrm{C}$. In experiments in which field potentials (FPs) were recorded oblique slices were used. Oblique slices $(350-400 \mu \mathrm{m})$ were cut at an angle of $50^{\circ}$ from the mid-sagittal plane (Finnerty et al., 1999).

Whisker deprivation. Beginning on either P7 or P14, a selected row (D) of whiskers was plucked from the right side of the face under isoflurane anesthesia. Deprivation was maintained by plucking these whiskers every other day until electrophysiological recordings were made on P12-P14 or P17-P21. Following the electrophysiology, recorded slices were stained for cytochrome oxidase activity by incubating in a solution containing $0.01 \%$ cytochrome $c$ (Sigma-Aldrich) and $0.05 \% 3,3^{\prime}$-diaminobenzidine (in $0.1 \mathrm{M}$ phosphate buffer, $\mathrm{pH} 7.4$ ) for overnight at $4^{\circ} \mathrm{C}$, to confirm correspondence between individual whiskers and recorded barrels in the slices.

Electrophysiology. Whole-cell patch pipettes (5-7 M 2 ) were used to record membrane voltage from visually identified pyramidal cells in layer $2 / 3$, under differential interference optics with an upright stage-fixed microscope (Olympus, BX51WI), as described previously (Itami et al., 2007). Micropipettes were pulled from borosilicate, thick-walled grass capillary tubes (Sutter Instruments). Pipette solution contained the following (in $\mathrm{mm}$ ): $130 \mathrm{~K}$-methane sulfonate, $10 \mathrm{KCl}, 10 \mathrm{HEPES}, 0.5$ K-EGTA, 5 MgATP, $1 \mathrm{NaGTP}$, and $10 \mathrm{Na}$-phosphocreatinine at pH 7.3 (295 mOsm). Responses were recorded using either a Multiclamp 700A or an Axoclamp 2B amplifier (Molecular Devices) in current-clamp mode. Signals were lowpass filtered at $3-5 \mathrm{kHz}$, digitally sampled at $10-20 \mathrm{kHz}$, and monitored using pCLAMP software (Molecular Devices). Upon inserting the electrode into the bath, stray pipette capacitance and the bridge balance were compensated using circuits built into the amplifier. The bridge balance was checked repeatedly and readjusted as necessary. A concentric bipolar stimulating electrode (FHC) was placed at layer 4 and used to apply square pulse electrical stimuli (100 $\mu \mathrm{s}$, $<0.5 \mathrm{~mA})$ every $7500 \mathrm{~ms}(0.133 \mathrm{~Hz})$, unless otherwise specified.

In some experiments, FPs were recorded from $\mathrm{L} 2 / 3$ in response to $\mathrm{L} 4$ stimulation, using glass micropipettes ( $1-3 \mathrm{M} \Omega, 5 \mu \mathrm{m}$ internal diameter) containing $5 \mathrm{~mm}$ bicuculline methiodide (Sigma-Aldrich) to block local $\mathrm{GABA}_{\mathrm{A}}$ inhibition. To distinguish artificial components from field responses, $1 \mu \mathrm{M}$ tetrodotoxin (Wako Pure Chemical Industries) solutions were bath applied at the end of recordings in the initial series of experiments. Field responses were measured from the baseline to the peak of the first negative component.

Induction protocol for STDP. Single postsynaptic action potentials (APs) were evoked by somatic current injection using the smallest current possible (typically $<1.5 \mathrm{nA}$ for $5-10 \mathrm{~ms}$ duration). Stimulus intensity to L4 was also adjusted to evoke EPSPs with a single component, without notches in the rising and decaying phases. The pairing interval was defined from the onset of EPSP to the peak of each AP. A total of 90 pairings was applied to presynaptic and postsynaptic cells with either fixed or randomized delays. For experiments with random delay stimulation (see Fig. 7), stimulation patterns were constructed using a custom program (LabVIEW; National Instruments) through an interface (USBX 116P; TechnoWave) to a Windows computer.

Drugs. D-(-)-2-amino-5-phosphonopentanoic acid (D-AP5) and autocamtide-2-related inhibitory peptide (AIP) were obtained from Tocris Bioscience ( $R \& D$ Systems/Techne). 1,2-bis (o-Amino phenoxy) ethane- $N, N, N^{\prime}, N^{\prime}$-tetraacetic acid, $4 \mathrm{Na}$ (BAPTA), $N$-[2[[[3-(4-Chlorophenyl)-2-propenyl] methylamino] methyl] phenyl]$\mathrm{N}$-(2-hydroxyethyl)-4-methoxybenzene sulphonamide (KN-93), TYADFIASGRTGRRNAI-NH $\mathrm{N}_{2}$, protein kinase A (PKA) inhibitor, and 6-22 amide (PKI 6-22) were obtained from Calbiochem (Merck/ EMD). Rp-adenosine 3',5'-cyclic monophosphorothioate triethylammonium salt hydrate (Rp-cAMP-S) was obtained from SigmaAldrich.

Statistical analysis. All values are presented as mean \pm SEM, unless otherwise specified. Hypothesis testing was performed with appropriate statistical tests, as specified with a significance level of either $p<0.05$ or $<0.01$, as indicated.

\section{Results}

Developmental switch in the properties of STDP

Consistent with an earlier report (Feldman, 2000), we observed that during the third postnatal week, pre-before-post $(+8 \mathrm{~ms}$, positive timing delay; +timing) and post-before-pre $(-8 \mathrm{~ms}$, negative timing delay; - timing) stimulus pairing at L4-L2/3 synapses produced long-term potentiation (t-LTP) and t-LTD, respectively (Fig. $1 A, B, E, F$ ). During the second postnatal week, however, both positive and negative timing delays elicited t-LTP in the majority of cases (Fig. $1 C-F$ ). In mice older than P15, positive $(+8 \mathrm{~ms})$ and negative $(-8 \mathrm{~ms})$ timing delays produced EPSPs with mean amplitudes $140.5 \pm 14.4 \%(n=17)$ and $74.7 \pm$ $7.8 \%(n=17)$, respectively, compared with control. While mice younger than P13 produced EPSPs of mean amplitudes $142.5 \pm$ $12.8 \%(n=23)$ and $150.7 \pm 16.0 \%(n=21)$, respectively, compared with control (Fig. $1 G$ ). Testing various pairing delays during the third postnatal week produced a classical bidirectional (t-LTP and t-LTD) STDP curve similar to those described previously (Feldman, 2000, 2009; Caporale and Dan, 2008) (Fig. 2A). However, during the second postnatal week, the resultant plot differs from that of the third postnatal week, especially with respect to the negative timing delays (Fig. $2 B$ ). When t-LTP and t-LTD were defined as a $\geq 5 \%$ change in EPSP amplitude from control ( $t-L T P \geq 105 \%$ of control, $t-L T D \leq 95 \%$ of control), the fraction of cells showing t-LTP and t-LTD, respectively, elicited by post-before-pre (-timing) stimulation was 15.4 and $76.9 \%$ of all cells tested during P14-P20 (Fig. 2C, -timing, P14-20). In contrast, 62.9 and $29.0 \%$ of all cells tested produced t-LTP and t-LTD, respectively, during P8-P13 (Fig. 2C, - timing, P8-P13). The difference in cell fractions was statistically significant $\left(\chi^{2}\right.$ test, $p<0.001)$. There was no significant difference in the fractions of t-LTP and t-LTD induced by pre-before-post (+ timing) stimulation between the second and the third postnatal weeks 

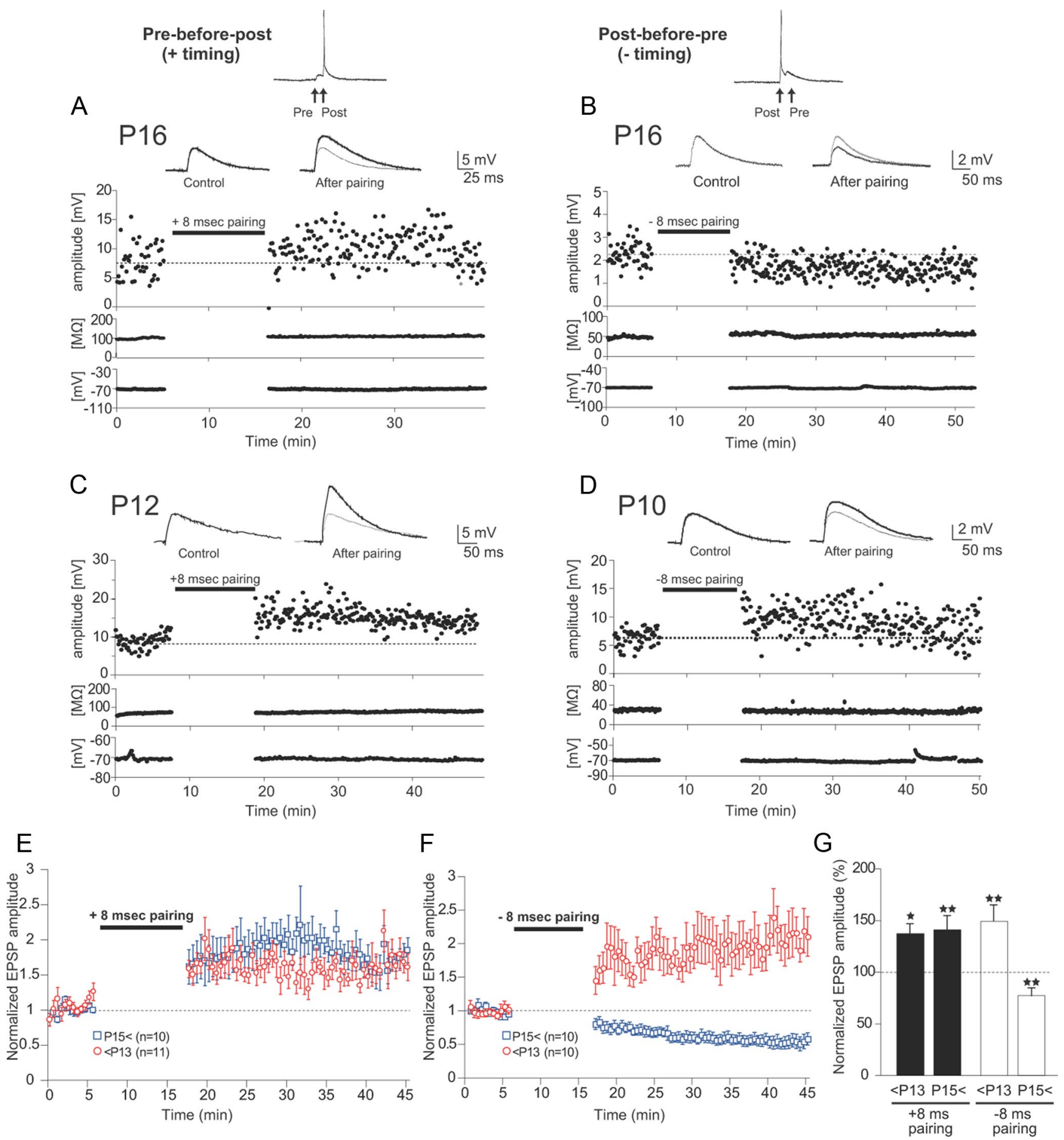

Figure 1. $\mathrm{t}-\mathrm{LTP}$ and $\mathrm{t}-\mathrm{LTD}$ during the second and third postnatal weeks. $A-D$, Examples of pre-post $(+8 \mathrm{~ms})$ and post-pre $(-8 \mathrm{~ms})$ timing stimulation at the indicated ages. During the third postnatal week (P16, $\boldsymbol{B})$, post-pre stimulation caused LTD ( $67.8 \pm 16.4 \%$ of control), while the same stimulation caused LTP $(\boldsymbol{D}, 125.1 \pm 30.2)$ during the second postnatal week. Sample recordings are displayed above. Input resistance (in $\mathrm{M} \Omega$ ) and membrane potentials (in $\mathrm{mV}$ ) are displayed below. $\boldsymbol{E}, \boldsymbol{F}$, Mean experiment time course across all cells for pre-post ( $+8 \mathrm{~ms}, \boldsymbol{E})$ and post-pre ( -8 $\mathrm{ms}, \boldsymbol{F}$ ) stimulation for ages $>$ P15 (squares) and $<$ P13 (circles) are shown. $\mathbf{G}$, Summary of the effect of pre-post ( $+8 \mathrm{~ms}$, filled bar) and post-pre stimulation $(-8$, open bar) during the second $(<\mathrm{P} 13)$ and third $(\mathrm{P} 15<)$ postnatal weeks. ${ }^{*} p<0.05$ and ${ }^{* *} p<0.01$.

(the fractions of t-LTP and t-LTD were 77.1 and $15.7 \%$ for P8$\mathrm{P} 13$ and 82.9 and $9.8 \%$ for $\mathrm{P} 14-\mathrm{P} 20$, respectively, $\chi^{2}$ test, $p=$ $0.67)$. This demonstrates that plasticity is strongly biased toward potentiation during the second postnatal week. Nevertheless, spike timing-dependency was still demonstrated during P7-P12 (Fig. $2 \mathrm{~B}$ ), because the magnitude of the plasticity was dependent on the delay of the stimulation (i.e., the shorter the delay, the larger the effect). This demonstrates bilateral STDP (potentiation for both positive and negative timing delay), compared with the classical bidirectional STDP (potentiation and depression) observed during the third postnatal week (Fig. 2A).

Plasticity was not observed when only EPSPs $(1 \mathrm{~Hz}, 90 \mathrm{~s})$ or only APs $(1 \mathrm{~Hz}, 90 \mathrm{~s}$, by current injection) were elicited (Fig. $2 D$; EPSPs only: $98.1 \pm 1.5 \%$ of control, $p=0.23, n=8$; APs only: $102.0 \pm 4.2 \%$ of control, $p=0.64, n=10$, two-tailed, one sample $t$ test). 
A

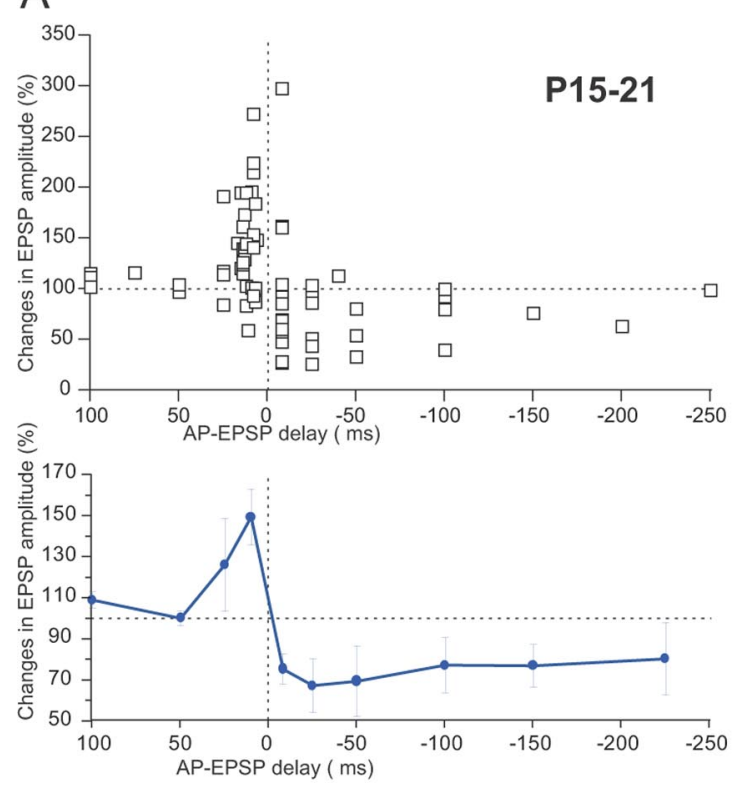

C
$\mathrm{B}$

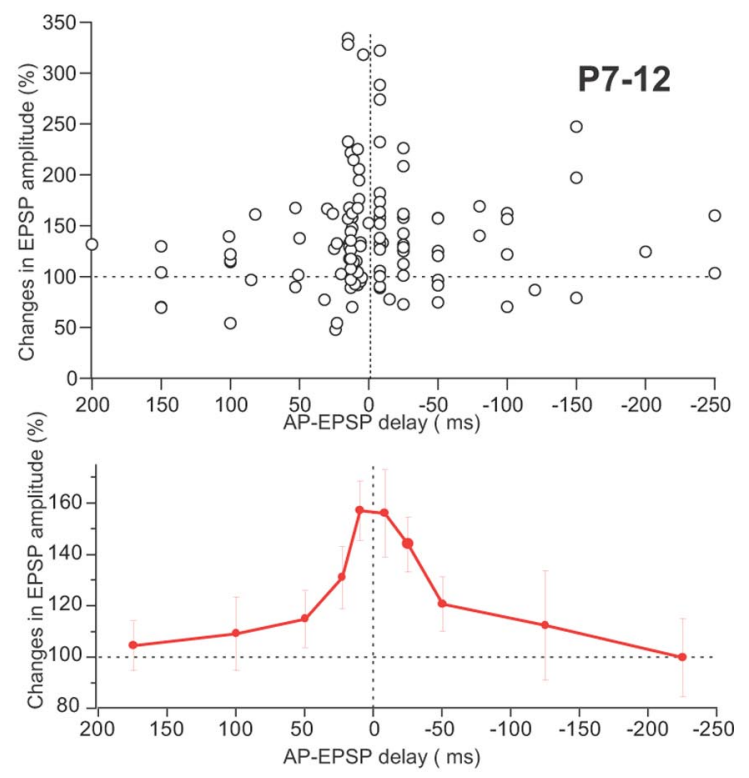

D

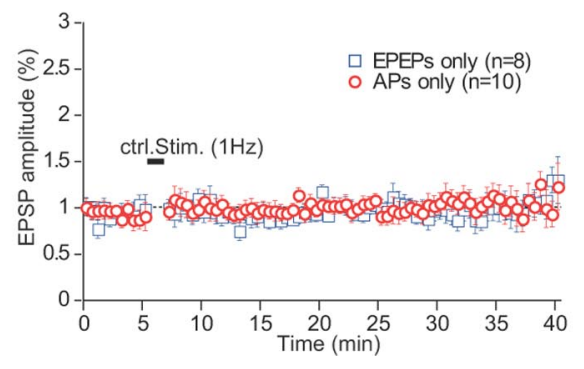

Figure 2. Developmental switch in STDP occurring at the end of the second postnatal week. $A, B$, The graphs show the relationship between applied timing delay and the resultant changes in EPSP amplitude for the indicated age groups. In the bottom graphs, connected lines indicate changes in EPSP amplitudes in 10 different pairing delay groups (mean \pm SEM). Ranges for delays were as follows: $A, 0$ to $+12 \mathrm{~ms},+25 \mathrm{~ms},+26$ to $+50 \mathrm{~ms},+51$ to $+100 \mathrm{~ms}$, and 0 to $-10 \mathrm{~ms},-11$ to $-25 \mathrm{~ms},-26$ to $-50 \mathrm{~ms},-51$ to $-100 \mathrm{~ms},-150 \mathrm{~ms}$, and -200 to $-250 \mathrm{~ms}$. $\boldsymbol{B}, 0$ to +12 $\mathrm{ms},+25 \mathrm{~ms},+26$ to $+50 \mathrm{~ms},+51$ to $+100 \mathrm{~ms},+150$ to $200 \mathrm{~ms}$, and 0 to $-10 \mathrm{~ms},-11$ to $-25 \mathrm{~ms},-26$ to $-50 \mathrm{~ms},-51$ to $-150 \mathrm{~ms}$, and -200 to $-250 \mathrm{~ms}$. C, Histograms showing the fractions of cells exhibiting LTP (gray), LTD (black), and no change (white) elicited by pre-before-post (+ timing) or post-before-pre ( - timing) stimulation during the second (P8 -P13) and third (P14-P20) postnatal weeks. LTP was defined as those EPSPs changed $\geq 5 \%$ (i.e., $\geq 105 \%$ of control), and LTD was defined as those that changed $\geq 5 \%$ (i.e., $\leq 95 \%$ of control). Histograms based on all data points in graphs $\boldsymbol{A}$ and $\boldsymbol{B}$ tested for various timing delays ranging from $+100 \mathrm{~ms}$ to $-250 \mathrm{~ms}$. Numbers in parentheses within the bars indicate the number of observed EPSPs. There was a significant difference between the second and third postnatal weeks for - timing stimulation $\left(\chi^{2}\right.$ test, $\left.p<0.001\right)$. $\boldsymbol{D}$, Neither presynaptic nor postsynaptic activity alone induced LTP. Plasticity was not observed when only EPSPs $(1 \mathrm{~Hz}, 90 \mathrm{~s})$ or only APs $(1 \mathrm{~Hz}, 90 \mathrm{~s}$, by current injection) were elicited without pairing with postsynaptic APs or presynaptic stimulations, respectively. When EPSPs alone were elicited, EPSP magnitude was $98.1 \pm 1.5 \%$ of control $(p=0.23, n=15)$, and when APs alone were elicited, EPSP magnitude was $102.0 \pm 4.2 \%$ of control $(p=0.64, n=10)$, based on a two-tailed, one sample $t$ test.

For negative timing delay, to determine how t-LTP transitions to t-LTD during development, the magnitude of plasticity (potentiation or depression) induced by negative timing delay $(-8$ or $-25 \mathrm{~ms}$ ) was plotted against age (Fig. $3 \mathrm{~A}$ ). Although some cells exhibited remarkable potentiation at $\mathrm{P} 7-\mathrm{P} 8$, across the cell population, the level of potentiation fell just short of statistical significance at this age $(148.9 \pm 26.7 \%$ of control $p=0.08, n=16$, two-tailed, one sample $t$ test), apparently because many cells were unresponsive to spike-timing stimulation. Significant potentiation was first observed at P9-P10 $(146.4 \pm 14.4 \%, p=0.0038$, $n=23$ ). At P11-P12, significant potentiation was again demonstrated $(135.3 \pm 14.2 \% p=0.028, n=13)$. At P13-P14, both potentiation and depression were induced. Therefore across the entire cell population a significant difference was not shown $(89.3 \pm 13.9 \%, p=0.45, n=16)$. After P14, only depressions were significantly induced (P15-P16: 69.4 $\pm 7.5 \%, p=0.0018$, $n=12$; P17-P18: $62.4 \pm 11.6 \%, p=0.007, n=13$; P19-P20: $40.8 \pm 5.8 \%, p=0.0005, n=5)$. Therefore, this analysis showed that the transition from t-LTP to t-LTD occurred at P13-P14. A similar result was obtained from linear regression analysis of the same data. Linear regression was used to estimate the age of transition from t-LTP to t-LTD (Fig. 3B). The resultant regression equation was as follows: Amplitude $=248.6-11.1 \times$ Age, $R^{2}=$ $0.27(p<0.0001)$. The theoretical day of transition, the point at which the regression line crossed a horizontal line located at an amplitude of $100 \%$, was P13.4 (Fig. 3B). Finally, successive plots of STDP curves at each developmental stage for a range including both positive and negative timing delays ( +100 to $-250 \mathrm{~ms}$ ) also indicate that the transition occurs at approximately P13-P14 (Fig. 4). STDP curves of each age group up to P11-P12 are approximately symmetric and are centered at $0 \mathrm{~ms}$ timing with positive values (potentiation) for the entire delay range, while for age groups $\geq \mathrm{P} 13-\mathrm{P} 15$ the curves became increasingly biphasic (indicating both potentiation and depression). This trend only increased and never reversed at later ages, indicating that transition from t-LTP to t-LTD occurred at approximately P13-P15. 
These results indicate that during the second postnatal week, L4-L2/3 synapses exhibit a distinct type of STDP that is strongly biased toward potentiation, and that classical bidirectional STDP begins to manifest at approximately P13-P15.

\section{Postsynaptic $\mathrm{Ca}^{2+}$ rise, the NMDA receptor, and PKA, but not calcium/ calmodulin-dependent protein kinase II are involved in the induction of t-LTP during the second postnatal week}

Earlier studies showed that LTP requires an NMDA receptor (NMDAR)-mediated rise in intracellular $\mathrm{Ca}^{2+}$ at the postsynaptic site, which in turn activates calcium/ calmodulin-dependent protein kinase II (CaMKII; Kelly et al., 1984; Miller and Kennedy, 1985; Malinow et al., 1989; Silva et al., 1992; Hayashi et al., 2000; Harding-

ham et al., 2003). We found that a postsynaptic rise in $\mathrm{Ca}^{2+}$ was required for induction of t-LTP by both positive and negative timing delay stimulations. Intracellular injection of the $\mathrm{Ca}^{2+}$ chelator BAPTA (1 mM) through the recording pipette blocked the induction of t-LTP by both positive and negative timing delays during the second postnatal week $(+8 \mathrm{~ms}$ delay: $98.7 \pm$ $13.3 \%, n=15$; -25 ms delay: $82.5 \pm 2.8 \%, n=12$; Fig. $5 A-C)$ in a similar manner as a previous study in which t-LTP was blocked after the third postnatal week (Bender et al., 2006b).

Pairing-induced t-LTP during the second postnatal week was also dependent on NMDAR activation, as the selective NMDAR antagonist D-AP5 (50 $\mu \mathrm{M}$ ) blocked t-LTP induction (Fig. $5 B, C$ ), just as it blocks t-LTP during the third postnatal week (Bender et al., 2006b). CaMKII activation was, however, not required for induction of t-LTP during the second postnatal week, because intracellular injection of KN-93 (5 $\mu \mathrm{M})$, a CaMKII inhibitor, was unable to block t-LTP induction, though it successfully blocked t-LTP during the third postnatal week (Fig. 5E), as previously shown in the LTP induction (Glazewski et al., 1996, 2000). The lack of involvement of CaMKII in t-LTP induction was also confirmed using a distinct CaMKII inhibitor, AIP, a highly potent and selective peptide substrate for CaMKII (Ishida et al., 1998). Addition of AIP blocked t-LTP after P15, but not before P13 (Fig. $5 E$ ). In contrast, during the second postnatal week t-LTPs elicited by both positive and negative timing delays were blocked by postsynaptic injection of the PKA inhibitor PKI 6-22 (20-40 $\mu \mathrm{M})$ (positive delay: $89.5 \pm 7.1 \%, n=26$; Fig. $5 E$; negative delay: $89.2 \pm 10.1 \%$ of control, $n=16$; Fig. $5 C$ ). However, PKI 6-22 failed to block t-LTP elicited by positive timing delay during the third postnatal week ( $126.8 \pm 1.5 \%$ of control, $n=8$; Fig. $5 E)$. Involvement of PKA in the t-LTP induction was also confirmed by another PKA inhibitor, Rp-cAMP-S, an inhibitor of the cAMP cascade, which blocked t-LTP before P13, but not after P15 (Fig. $5 D, E)$.

The mechanism underlying t-LTD has yet to be clarified, but a cannabinoid-dependent signaling mechanism has previously been suggested (Sjöström et al., 2003; Bender et al., 2006b; Kano et al., 2009). The possibility that t-LTD is mediated by cannabinoid receptors was investigated using AM251 (5 $\mu \mathrm{M}$, bath application), an antagonist against cannabinoid receptor 1 (CB1R). Post-pre timing stimulation $(-35 \mathrm{~ms})$ failed to induce t-LTD in the presence of AM251 (97.7 $\pm 4.1 \%$ of control, $p=0.58, n=9$ : two-tailed, one sample $t$ test), indicating that t-LTD was mediated by CB1R. These results
B

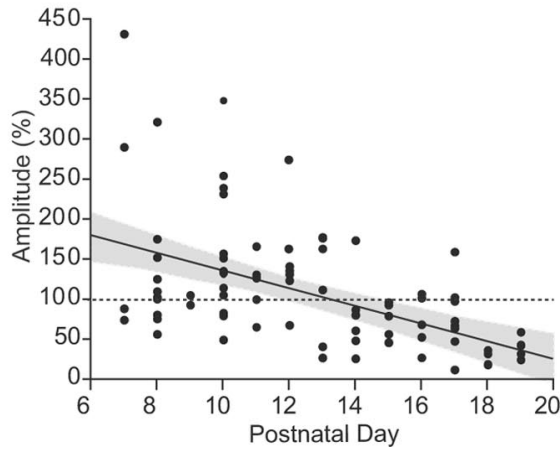

indicate that between the second and third postnatal week, a PKA-dependent t-LTP-inducing mechanism is replaced by a CaMKII-dependent t-LTP-inducing mechanism and a CB1Rdependent t-LTD-inducing mechanism.

\section{Deprivation-induced suppression of $\mathrm{L} 4-\mathrm{L} 2 / 3$ transmission is not induced under bilateral STDP}

Both LTP and LTD are thought to play crucial roles in experience-dependent map plasticity. Acute single whisker deprivation suddenly reverses the spike sequences into " $\mathrm{L} 2 / 3$ followed by L4" in the deprived column (Celikel et al., 2004). This is because when a single whisker is deprived, cross-columnar inputs from surround whiskers activate L4, L2/3 cells in the deprived column, which are functionally rapid in L2/3, but relatively slow in L4, causing a reversal of spike sequences (Celikel et al., 2004). Such reversed spike sequences could lead to deprivation-induced suppression of synaptic transmission based on t-LTD under the classical bidirectional STDP (Celikel et al., 2004; Bender et al., 2006a), causing shrinkage of the receptive field. That L4-L2/3 synapses in the barrel cortex are strongly biased toward LTP during the second postnatal week may imply that deprivationinduced suppression at this synapse does not occur during that period. In contrast, suppression may still be induced because there are multiple forms of LTD in the cortex (Malenka and Bear, 2004; Massey and Bashir, 2007). Other forms of LTD or even some unknown forms of LTD may compensate for the lack of t-LTD and cause deprivation-induced suppression. To examine whether deprivation causes synaptic weakening at $\mathrm{L} 4-\mathrm{L} 2 / 3$ transmission, whisker deprivation was performed with P7 animals every other day until electrophysiological recordings were performed at either P12-P14 or P17-P20. This experiment was designed to determine whether deprivation-induced suppression could be detected while t-LTD is largely lacking, and whether deprivation-induced suppression appears in parallel with t-LTD in the third postnatal week during development.

We examined synaptic transmission at L4-L2/3 synapses in oblique slices (Finnerty et al., 1999) containing columns representing each of the five whisker rows (A-E) (Allen et al., 2003; Bender et al., 2006a). FPs were recorded from L2/3 in response to L4 stimulation in the same column (Allen et al., 2003). For each column, the stimulus threshold was determined and strengthresponse curve was then constructed. FPs consisted of fast negativity followed by a slow envelope. Based on its latency and 

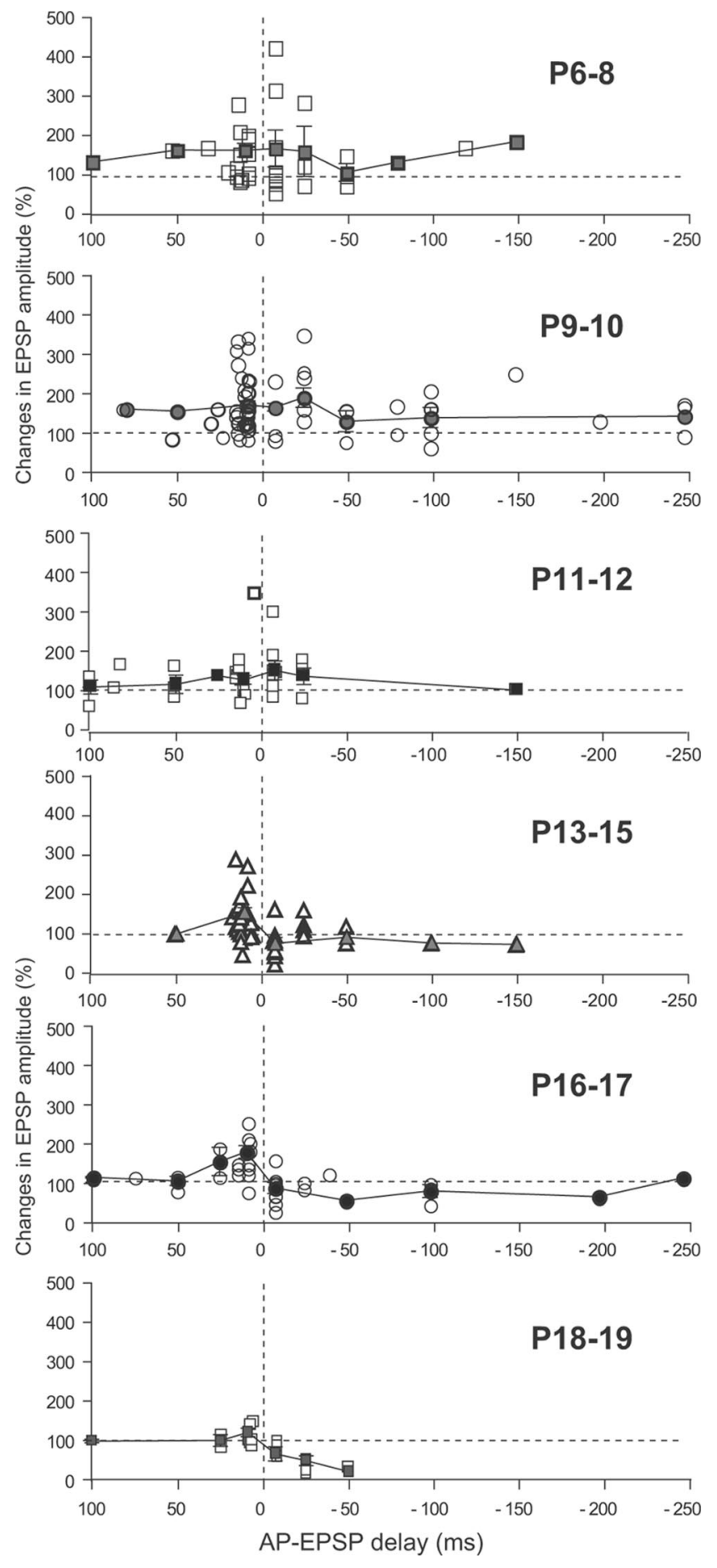

Figure 4. Changes in the STDP curve every $2 \mathrm{~d}$ during the second and third postnatal week. Various timings of pre-post and post-pre stimulations were applied and the effect breakdown is illustrated for each age group. The graphs indicate that before P13, bilateral STDPs (potentiation for both positive and negative timing delays) were consistently induced, whereas after P14 classical bidirectional STDP (potentiation by positive timing delay and depression by negative timing delay) were induced. Connected lines represent mean \pm SEM.

sensitivity to glutamate receptor antagonists, the fast negativity was considered to represent the monosynaptic component, as previously reported (Allen et al., 2003)(Fig. 6B1,B2, middle). In slices from mice deprived of their $\mathrm{D}$ row of whiskers during the second postnatal week (P7 to P12-P14), there were no significant differences between the amplitudes of FPs in the deprived and spared columns $(p>0.01$, repeated-measures ANOVA, post hoc test; Fig. 6 B1,C1; Table 1). However, when the deprivation was maintained until P17-P20, FPs from the D row were significantly reduced (Fig. 6 B2,C2, Row D: $4.79 \pm 0.33 \mathrm{mV}$, other rows ranged from 5.76 to $6.50 \mathrm{mV}, p<0.01$, repeated-measures ANOVA, post hoc test; Table 1). This result could potentially indicate that whisker deprivation does not induce synaptic depression during the second postnatal week. It is possible, however, that P7 to P17-P20 deprivation weakened L4-L2/3 transmission simply because the deprivation lasted longer (10-13 d) than P7 to P12-P14 (5-7 $\mathrm{d}$ of deprivation). To test this possibility, another series of deprivation experiments were performed, in which whiskers were deprived from P14 to P18-P20 (4-6 d), during the third postnatal week, and the strength of $\mathrm{L} 4-\mathrm{L} 2 / 3$ transmission was assessed. Results showed that $4-6 \mathrm{~d}$ of deprivation during the third postnatal week was enough to weaken L4-L2/3 transmission only in the deprived column (Fig. 6C3, Row D: $5.81 \pm 0.21 \mathrm{mV}$, other rows ranged from 6.43 to $7.21 \mathrm{mV}, p<0.01$, repeated-measures ANOVA, post hoc test; Table 1).

These experiments strongly indicate that whisker deprivation does not induce synaptic depression during the second postnatal week, when t-LTD is difficult to induce, but the same manipulation during the third postnatal week is fully capable of inducing synaptic depression in the deprived column.

\section{Potentiation, instead of depression, was induced when EPSPs were uncorrelated with postsynaptic APs during the second postnatal week}

Together these results show that bilateral STDP during the second postnatal week could not cause deprivation-induced suppression. Does this plasticity mechanism have any physiological significance? Whisker stimulation induces sequential L4 followed by L2/3 activity in the principal column (Simons, 1978; Armstrong-James et al., 1992; Armstrong-James, 1995; Brumberg et al., 1999; Celikel et al., 2004). Under the classical bidirectional STDP rule, uncorrelated presynaptic and postsynaptic cell activity within a range of -50 to $+50 \mathrm{~ms}$ leads to t-LTD (Feldman, 2000), which is reasonable, considering that an integral component of the bidirectional STDP curve is negative. This raises the question of what happens if the same uncorrelated activity that likely occurs between L4 and L2/3 cells during the second postnatal week is applied to these synapses, which are undergoing bilateral STDP at that age. Considering that an integral component of the bilateral STDP curve within $\pm 50 \mathrm{~ms}$ should be positive, because it is strongly biased to LTP, uncorrelated activity should result in potentiation. This possibility was directly tested by applying computer-determined random-delay timing stimulations (Fig. $7 A-E$ ) to presynaptic and postsynaptic cells. Figure $7 B$ illustrates the even distribution (Flat random), within the range of $\pm 50 \mathrm{~ms}$, of the delays in the pre-post stimulations (AP-EPSP delay) for the 90 stimuli (Fig. 7A), as more clearly seen in the histogram (Fig. 7C). This random stimulation protocol led to t-LTD during the third postnatal week (Fig. 7F; $\mathrm{P} 15<, 65.0 \pm 6.1 \%$ of control, $p=0.0001$, two-tailed one sample $t$ test, $n=12$ ), confirming an earlier report (Feldman, 2000). In contrast, the same random stimulation led to robust t-LTP during the second postnatal week (Fig. $7 F ;<\mathrm{P} 13,148.7 \pm 13.9 \%$ of control, $p=0.0056, n=11$ ), and led to no change during the P13-P15 time period (Fig. 7G, left, Flat random: $99.6 \pm 9.3 \%$ of control, $p=0.97$, two-tailed one-sample $t$ test, $n=8$ ). Another "random" stimulation pattern was also tested, in which pre-post timing delays with a Gaussian distribution were delivered (Fig. $7 D, E)$. The "Gaussian random" stimulation results in potentia- 
A

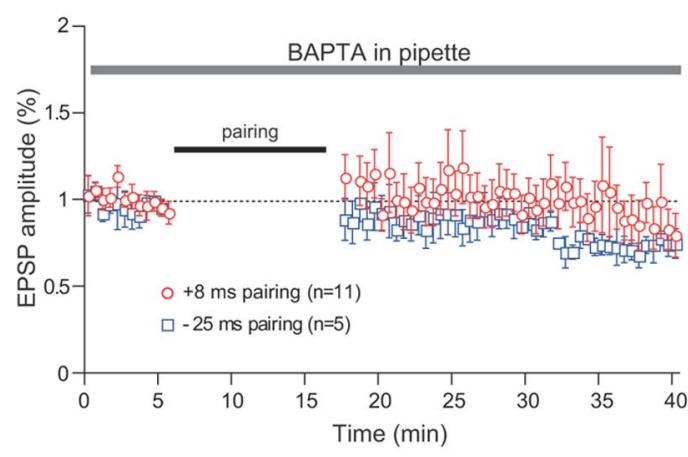

D

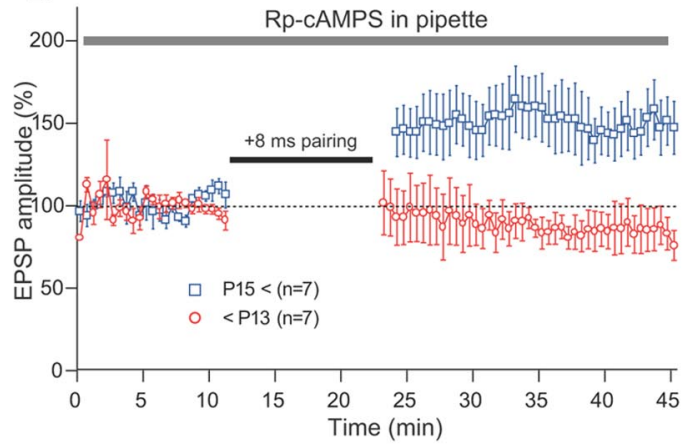

B

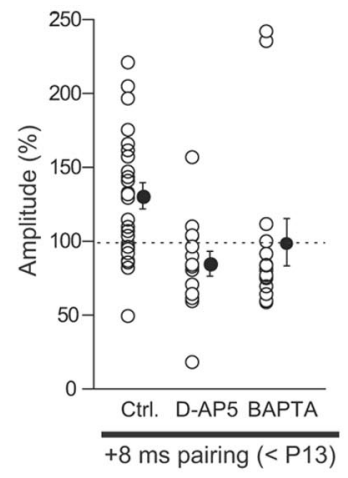

C

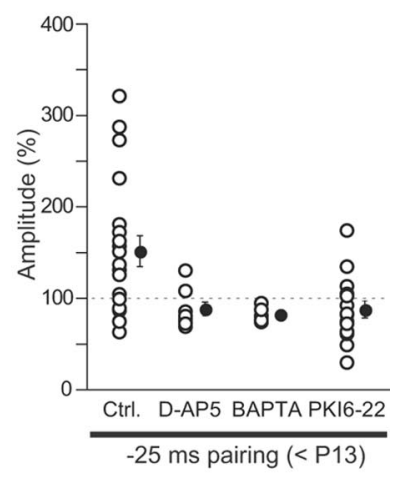

E

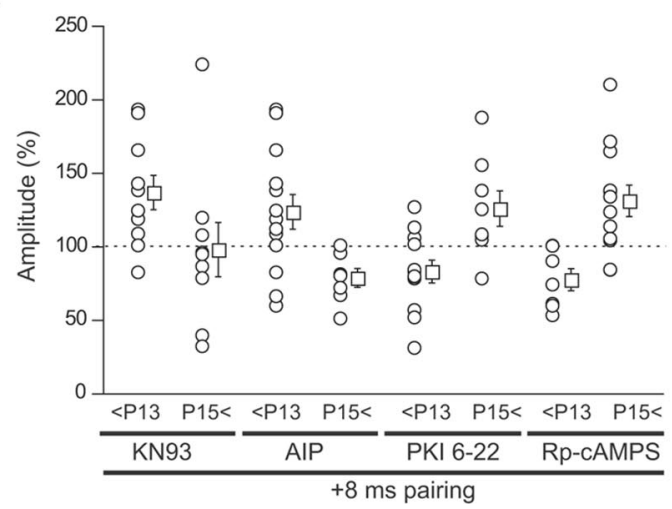

Figure 5. After P15, t-LTP was CaMKII dependent, but was PKA dependent before P13. A, BAPTA, a Ca ${ }^{2+}$ chelator, in the recording pipettes (1 mm) blocked the induction of LTP by both pre-post $(+8 \mathrm{~ms})$ and post-pre ( $-25 \mathrm{~ms})$ stimulation, as also summarized in $\boldsymbol{B}$ and $\boldsymbol{C} . \boldsymbol{B}, \boldsymbol{C}, \mathrm{D}-\mathrm{AP5}(50 \mu \mathrm{m})$ applied to the bath blocked LTP induction by pre-post $(\boldsymbol{B})$ and post-pre $(\boldsymbol{C})$ stimulation. $\boldsymbol{D}, \boldsymbol{E}$, Rp-CAMP-S, a PKA inhibitor, as well as PKI 6-22, another PKA inhibitor, applied to postsynaptic cells through the recording pipette blocked the induction of LTP by pre-post stimulation only during the second postnatal week (D), which is summarized in the right columns of $\boldsymbol{E}$. LTP by negative timing ( $-25 \mathrm{~ms})$ at $<$ P13 was also inhibited by PK I6 - 22 ( $\boldsymbol{C}$ ). In contrast, KN-93 and AIP, both CaMKII inhibitors, blocked LTP induction only during the third postnatal week $(\boldsymbol{E})$. In all graphs, points represent mean \pm SEM.

tion before P13 $(167.0 \pm 18.0 \%$ of control, $n=10)$, no change at P13-P15 (97.0 $\pm 10.2 \%$ of control, $n=15)$, and depression after P15 $(68.2 \pm 8.1 \%$ of control, $n=11)$, which were not significantly different $(p=0.43,0.87$, and 0.39 , for $<\mathrm{P} 13$, P13-P15, and $>$ P15, respectively; unpaired Student's $t$ test) when compared with the "Flat random" stimulation (Fig. 7G).

These results clearly indicate that during the second postnatal week correlated activity, or closely associated firing of L4 and L2/3 cells, leads to stronger connections, regardless of spiking order. In addition to this temporal association, however, spiking order becomes highly important in determining the direction of the change in the synaptic connections beginning in the third postnatal week.

\section{Discussion}

This study demonstrated that L4-L2/3 synapses exhibit a novel plasticity mechanism that operates only during the second postnatal week, and that this mechanism is replaced by the better characterized, classical bidirectional STDP mechanism in the third postnatal week. Map plasticity requires both LTD and LTP, corresponding to loss and gain of receptive field, respectively. However, following sensory (whisker) deprivation, bilateral STDP during the second postnatal week was profoundly biased toward LTP, which results in whisker deprivation being unable to induce suppression of synaptic strength at L4-L2/3 synapses in the deprived column. These results imply that map reorganization may be impaired under bilateral STDP.

\section{t-LTD during the second postnatal week: comparison with a previous study}

In the current study, STDP was strongly biased toward potentiation until the end of the second postnatal week. However, one previous study reported that post-pre timing stimulation did not cause t-LTP, but solely induced t-LTD (Banerjee et al., 2009). Therefore, the previous study only observed classical bidirectional STDP from the end of the first postnatal week and failed to observe a developmental switch in STDP, as described in the current study (Banerjee et al., 2009). Throughout this study, the relationship between post-pre timing and resultant plasticity was extensively examined to attempt to address this discrepancy, but the current results consistently indicated that both potentiation and depression were induced in the negative timing delays, with a heavier bias toward potentiation at every developmental stages up to P12 (Figs. 3, 4). Therefore, it is likely that the discrepancy is not due to differences in the specific ages or specific post-pre timings used. One important difference between these two studies is that t-LTD in the previous study is not dependent on CB1Rs, while t-LTD in the classical bidirectional STDP is CB1R dependent (Sjöström et al., 2003; Bender et al., 2006b). In the present study, results confirmed that t-LTD was blocked in the presence of AM251, and was thus CB1R dependent. These results indicate that distinct t-LTDs may exist and that the CB1R-dependent t-LTD begins to appear at L4-L2/3 synapses predominantly from the third postnatal week. If these two distinct t-LTDs are specifically associated with distinct afferent inputs, the differences be- 
A

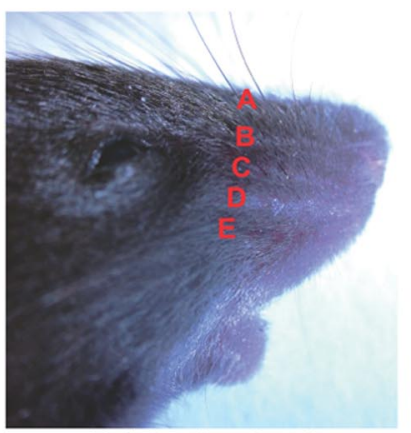

\section{Experimental day}

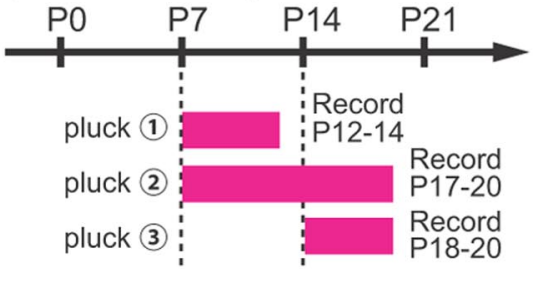

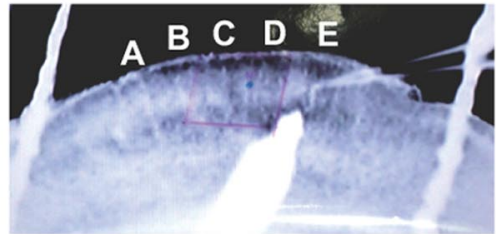

Electrophysiology

D1-8 plucked
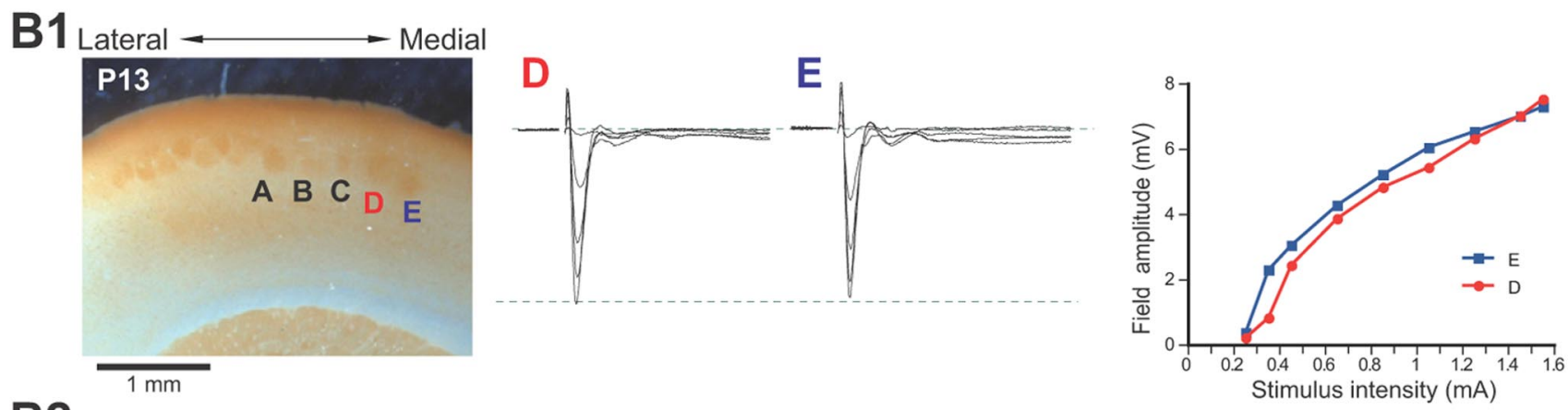

B2
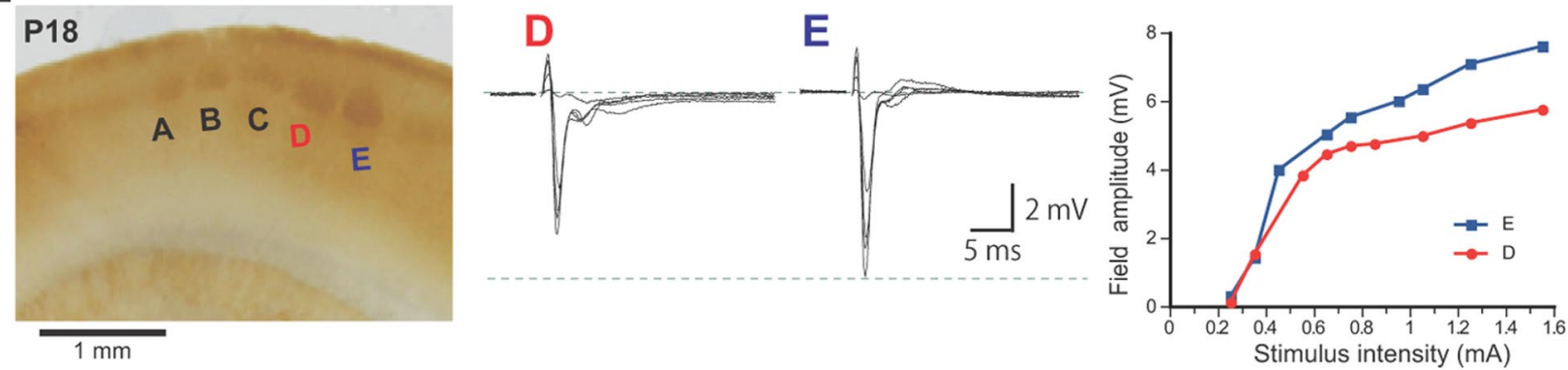

\section{C1}

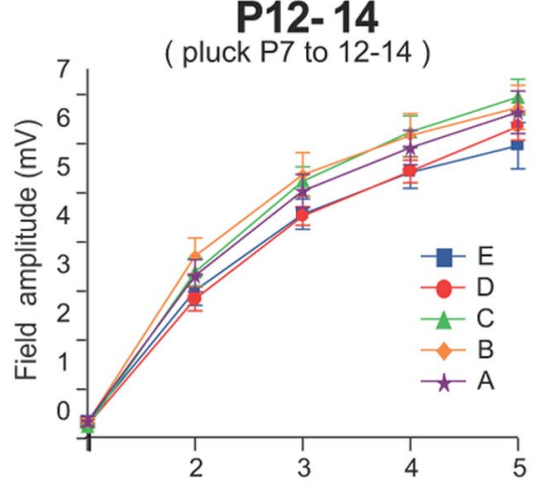

Stimulus intensity $(\mathrm{n} \times$ threshold $)$
C2

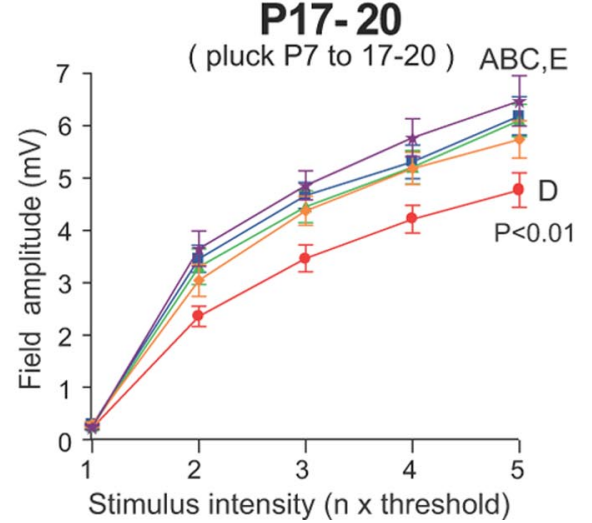

\section{C3}

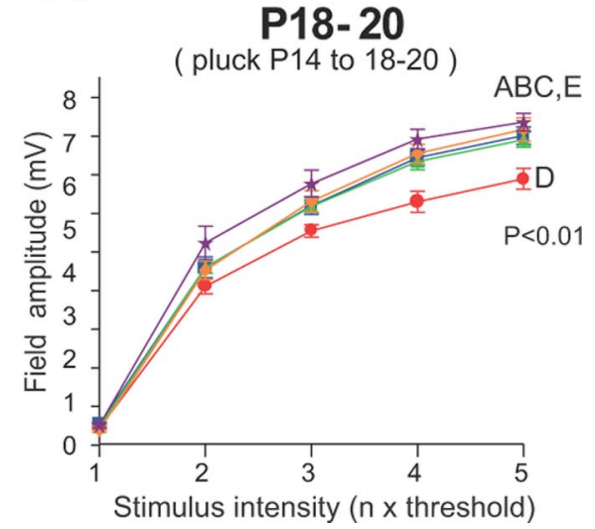

Figure 6. Whisker deprivation fails to induce suppression of L4-L2/3 transmission until P12-P14.A, Left, Photograph illustrating the right-sided whiskers of a mouse. All whiskers in Row D were plucked, with the other whiskers left intact. Middle, Whisker plucking and electrophysiological recording schedule. Right, Photograph of a brain slice from the barrel cortex in the recording chamber, showing the barrels corresponding to whiskers A-E. A stimulating electrode was placed on $L 4$ of column $E$ and the tip of a glass micropipette was placed at $L 2 / 3$ of column E for recordings. B1, B2, Two examples of cytochrome oxidase staining (left), FP recordings (middle), and stimulus-response curves constructed from the FPs (right). Slices were prepared from P13 (B1) and P18 (B2) mice. C1-C3, Summary of mean stimulus-response curves from all slices from (C1) P12-P14 ( $n=14),($ (2) P17-P20 ( $n=24)$, and (C3) P18-P20 ( $n=28)$.

tween the current results and those from the previous study may stem from differential activation of distinct fiber types (e.g.) spiny stellate vs star pyramid, or L4 vs passing fibers from thalamic afferents, some of which directly innervate L $2 / 3$ cells) (Ferster and Lindstrom, 1983; Kimura et al., 1989; Shirokawa et al., 1989).
PKA and spontaneous activity, induce t-LTP at immature synapses compared with CaMKII and sequential activity at mature synapses

In adult hippocampus, LTP is expressed by GluR1 delivery to postsynaptic sites through CaMKII activity (Hayashi et al., 2000; 
Table 1. Mean maximal FPs in columns from D row-deprived animals

\begin{tabular}{lllllll}
\hline Age at recording (plucked from) & Threshold & A & B & C & D \\
\hline P12-P14 (P7 ) & $\times 1$ & $0.35 \pm 0.10(11)$ & $0.33 \pm 0.08(13)$ & $0.24 \pm 0.04(12)$ & $0.28 \pm 0.04(14)$ & $0.34 \pm 0.07(14)$ \\
& $\times 2$ & $3.31 \pm 0.33(11)$ & $3.71 \pm 0.37(13)$ & $3.39 \pm 0.28(12)$ & $2.84 \pm 0.24(14)$ & $3.01 \pm 0.30(14)$ \\
& $\times 3$ & $5.04 \pm 0.34(11)$ & $5.37 \pm 0.45(13)$ & $5.24 \pm 0.29(12)$ & $4.53 \pm 0.19(13)$ & $4.57 \pm 0.31(14)$ \\
& $\times 4$ & $5.92 \pm 0.35(11)$ & $6.17 \pm 0.45(13)$ & $6.24 \pm 0.33(12)$ & $5.44 \pm 0.23(14)$ & $5.42 \pm 0.32(14)$ \\
& $\times 5$ & $6.64 \pm 0.43(11)$ & $6.74 \pm 0.45(13)$ & $6.95 \pm 0.36(12)$ & $6.35 \pm 0.28(14)$ & $5.96 \pm 0.47(13)$ \\
P17-P20 (P7 ) & $\times 1$ & $0.25 \pm 0.05(11)$ & $0.30 \pm 0.05(14)$ & $0.25 \pm 0.03(15)$ & $0.23 \pm 0.03(24)$ & $0.29 \pm 0.05(22)$ \\
& $\times 2$ & $3.67 \pm 0.34(11)$ & $3.06 \pm 0.32(14)$ & $3.32 \pm 0.34(15)$ & $2.37 \pm 0.19(24)$ & $3.47 \pm 0.26(22)$ \\
& $\times 3$ & $4.88 \pm 0.28(11)$ & $4.40 \pm 0.28(14)$ & $4.47 \pm 0.30(15)$ & $3.49 \pm 0.26(23)$ & $4.69 \pm 0.25(22)$ \\
& $\times 4$ & $5.80 \pm 0.37(11)$ & $5.21 \pm 0.31(14)$ & $5.23 \pm 0.32(15)$ & $4.24 \pm 0.27(23)$ & $5.33 \pm 0.32(19)$ \\
& $\times 5$ & $6.50 \pm 0.48(10)$ & $5.76 \pm 0.36(12)$ & $6.13 \pm 0.31(12)$ & $4.79 \pm 0.33(17)$ & $6.21 \pm 0.37(12)$ \\
P18-P20 (P14 ) & $\times 1$ & $0.41 \pm 0.07(10)$ & $0.30 \pm 0.04(17)$ & $0.42 \pm 0.04(23)$ & $0.30 \pm 0.02(26)$ & $0.40 \pm 0.03(28)$ \\
& $\times 2$ & $4.19 \pm 0.39(11)$ & $3.58 \pm 0.26(17)$ & $3.96 \pm 0.15(23)$ & $3.26 \pm 0.16(26)$ & $3.75 \pm 0.21(28)$ \\
& $\times 3$ & $5.59 \pm 0.33(11)$ & $5.02 \pm 0.32(17)$ & $5.32 \pm 0.22(24)$ & $4.41 \pm 0.16(26)$ & $4.90 \pm 0.20(28)$ \\
& $\times 4$ & $6.72 \pm 0.26(11)$ & $6.14 \pm 0.35(16)$ & $6.23 \pm 0.28(25)$ & $5.27 \pm 0.20(24)$ & $5.87 \pm 0.21(28)$ \\
& $\times 5$ & $7.21 \pm 0.26(10)$ & $6.72 \pm 0.40(14)$ & $6.90 \pm 0.28(24)$ & $5.81 \pm 0.21(22)$ & $6.43 \pm 0.21(26)$ \\
\hline
\end{tabular}

All values are in $\mathrm{mV}$. The number of cortical columns is shown in parentheses. Significant difference was seen between D and other rows at P17-P20 (deprived from P7) as well as P18 -P20 (deprived from P14) ( $p<0.01$, repeated measures of ANOVA, post hoc test).

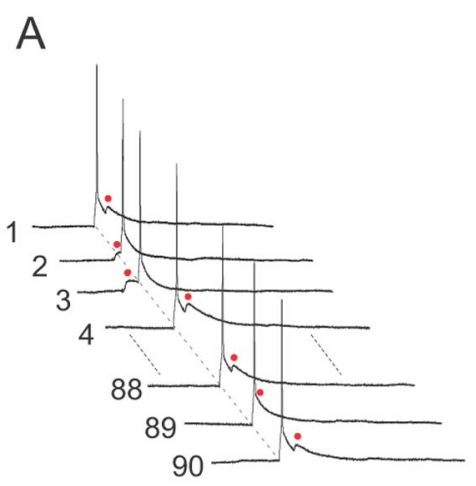

$\mathrm{F}$

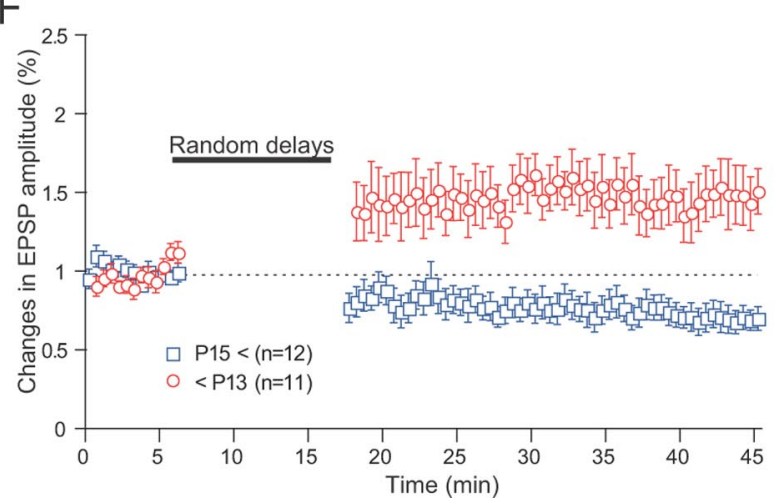

B

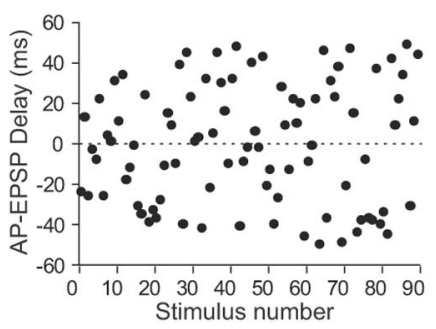

$D$

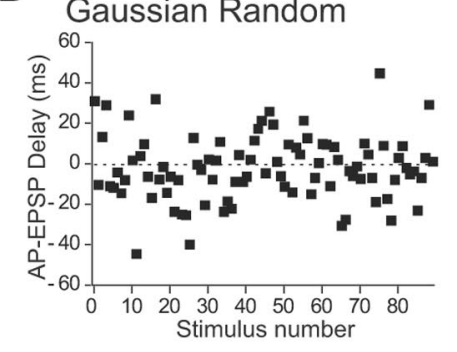

C

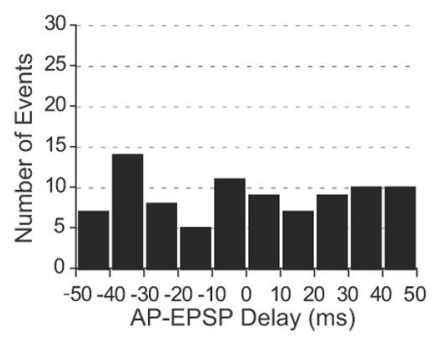

$E$

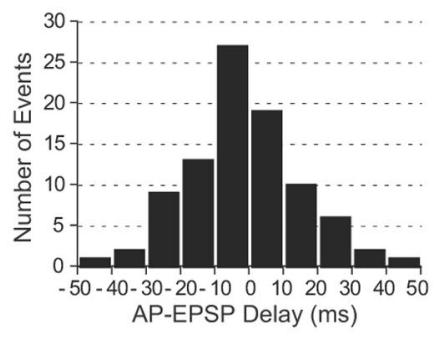

G

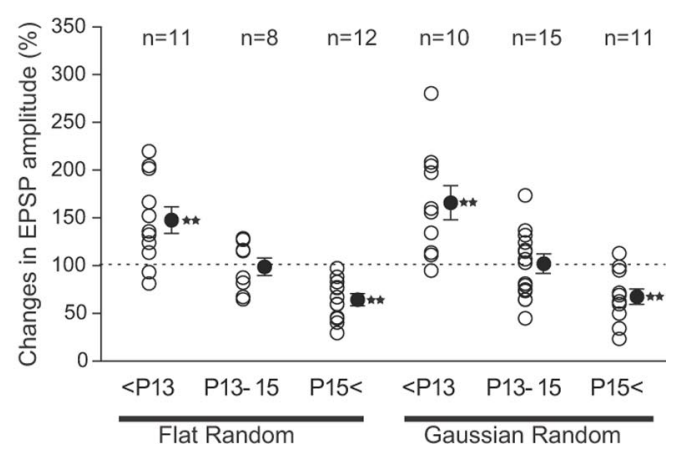

Figure 7. Random-delay timing stimulation causes potentiation before P13, while depression after P15. A, Example of random-delay stimulation. EPSPs were elicited by presynaptic stimulation (shown by red dots) and APs were elicited by postsynaptic current injection such that the delay between the AP and EPSP (AP-EPSP delay) was randomly distributed as also illustrated in $B$ and $C$. $\boldsymbol{B}$, AP-EPSP delays ( +50 to $-50 \mathrm{~ms}$ ) were plotted for the 90 stimuli. $C$, Histogram of AP-EPSP delays ( +50 to $-50 \mathrm{~ms}$ ) showing that delays were evenly distributed in this range. $\boldsymbol{D}$, AP-EPSP delays $(+50$ to $-50 \mathrm{~ms}$ ) plotted for the 90 stimuli, in which AP-EPSP delays were randomly distributed in a Gaussian manner. $E$, Histogram of AP-EPSP delays ( +50 to $-50 \mathrm{~ms})$ showing that the distribution is random in a Gaussian manner. $\boldsymbol{F}$, The mean time course across all cells following random delay stimulation are shown for the second (red circle) and third (blue square) postnatal week, causing LTP and LTD, respectively. G, Developmental changes in the effect of random-delay stimulation. Random-delay stimulation led to LTP during the second postnatal week, but LTD during the third postnatal week, and the transition occurred at P13-P15. Asterisks represent significance, ${ }^{* *} p<0.01$. 
Lisman et al., 2012). During development, before P10, LTP is mediated by PKA (Yasuda et al., 2003). Further studies revealed that LTP in the immature hippocampus was expressed by a delivery of GluR4 subunit through PKA activation (Zhu et al., 2000; Esteban et al., 2003), which is driven by spontaneous neuronal activity. This type of developmental switch is reasonable, because the amount of CaMKII and GluR1 are developmentally regulated and are not abundant in the forebrain until the third postnatal week (Sugiura and Yamauchi, 1992; Zhu et al., 2000). PKA and GluR4-dependent LTP (Zhu et al., 2000) was induced by spontaneous activity in the hippocampus, implying that even random firing of presynaptic and postsynaptic cells may lead to LTP. Therefore, hippocampal and barrel cortex development share some common features. This may predict that bilateral STDP operates at immature hippocampal synapses before P10, analogous to the L4-L2/3 synapses in the barrel cortex during the second postnatal week. Conversely, it is predicted that GluR4 delivery is involved in the L4-L2/3 LTP in the barrel cortex during the second postnatal week. This hypothesis was supported by a recent work that showed that spontaneous activity drives GluR4, but not GluR1 subunits, at L4-L2/3 synapses during P8P10 (Miyazaki et al., 2012), while the same experimental procedure drives GluR1, instead of GluR4 during P12-P14 (Takahashi et al., 2003).

\section{Spike sequence and spontaneous activity and their relevance to bidirectional STDP}

Based on results from a morphological study, the second postnatal week is an important time for synapse formation from L4 to L2/3 (Bender et al., 2003). During synapse formation, the spiking order between L4 and L2/3 cells is unstable or even random due to weakness or absence of synaptic connections. Moreover, as suggested previously, spike sequences cannot be well controlled before establishment of fast feedforward inhibition that takes place at the end of the second postnatal week (Kimura et al., 2010). Nevertheless, the immature bilateral STDP rule is suitable for strengthening synaptic connections between L4 and L2/3 cells under such unregulated spike sequences, because only the closer temporal correlation, regardless of spiking order, is required for strengthening the synapses. This may result in overinnervation, beyond the column border, as has actually been reported (Bender et al., 2003). Such noncolumnar innervation could be later pruned by the classical bidirectional STDP rules starting in the third postnatal week, as suggested by findings showing that whisker stimulation produces sequential firings in L4-L2/3 synapses (Simons, 1978; Armstrong-James et al., 1992; ArmstrongJames, 1995; Brumberg et al., 1999; Celikel et al., 2004), possibly only in the principal columns (Kimura et al., 2010). This developmental progression and transition of STDP rules is consistent with recent studies demonstrating that extensive circuit refinement takes place only from the end of the second postnatal week (P12). Interestingly, the end of the second postnatal week corresponds to the initiation of the critical period, as revealed by depriving all the whiskers except one (Wen and Barth, 2011), although there is a slightly different definition of the critical period (Stern et al., 2001). Thereafter, neuronal responses to whisker stimulation in L2/3 cells become reliable and precise, while such changes do not occur on L4 cells (Benedetti et al., 2009), consistent with the idea that L4-L2/3 synapse plasticity underlies refinement of responses.
These results strongly indicate that a developmental switch in STDP from bilateral to classical bidirectional is highly relevant to the initiation of the critical period.

In addition, during neuronal circuit formation, it has often been shown throughout the central and peripheral nervous systems across various species that afferent axons first make multiple, exuberant connections followed by elimination of excessive synapses, sometimes in an activity-dependent manner. Examples can be found in callosal connections in monkeys (LaMantia and Rakic, 1990), motoneuronal innervation to muscles (Brown et al., 1976), and preganglionic innervation to submandibular ganglion cells (Lichtman, 1977). A developmental switch in STDP mechanism may account for at least some of these phenomena, suggesting a lucrative area for future research.

\section{Possible saturation of potentiation after P15}

It is well known that excitatory synaptic potentiation cannot be rapidly induced at $\mathrm{L} 4-\mathrm{L} 2 / 3$ synapses after $\mathrm{P} 15$. Is this consistent with the current model of developmental transition of STDP? One possible explanation might be saturation of potentiation. As we have seen, signaling cascade leading to potentiation changes from PKA to CaMKII (Fig. 5), and that the time of transition occurs at approximately P13-P15. If the established spike sequence of "L4 followed by L2/3" is formed at P12-P14 (Benedetti et al., 2009), through possible maturation of feedforward FS neurons (Kimura et al., 2010), the L4-L2/3 synapses continuously receive $\mathrm{t}$-LTP-inducing stimulation from every whisker movement. This may saturate the capacity of potentiation at this synaptic site and is consistent with the results showing that depression can be induced relatively easily by whisker deprivation in the deprived column (Fig. 6) and with results from previous studies (Allen et al., 2003; Celikel et al., 2004; Bender et al., 2006a).

\section{Relevance of GABA maturation to plasticity}

In the visual cortex, initiation of the critical period is hypothesized to require maturation of FS-GABAergic circuits (Hensch et al., 1998; Fagiolini et al., 2004) (for review, see Hensch, 2005); but it is not yet known why maturation of inhibitory neurons is required for plasticity. In the barrel cortex, it is not well established whether GABAergic maturation is also required for plasticity to occur (but see Nowicka et al., 2009). However, the results of this study suggest that if the STDP rule switches at approximately P13-P15, spike sequence at L4-L2/3 synapses suddenly become important after the transition. Previous work suggested that maturation of thalamic innervation to FS cells in L4 may be highly relevant to establishment of "L4 followed by L2/3" spike sequences in response to whisker stimulation (Kimura et al., 2010), and that this maturation is complete at approximately P12-P14, simultaneous with the electrophysiological maturation of FS cell properties (Itami et al., 2007). Together, these results seem to indicate that STDP switch, maturation of FS cells, and thalamic innervation to FS cells progress in parallel to enable deprivation-induced suppression of $\mathrm{L} 4-\mathrm{L} 2 / 3$ transmission, in response to well controlled spike sequences of L4 and L2/3 cells generated by whisker inputs from the end of the second postnatal week.

\section{References}

Agmon A, Connors BW (1991) Thalamocortical responses of mouse somatosensory (barrel) cortex in vitro. Neuroscience 41:365-379. 
Allen CB, Celikel T, Feldman DE (2003) Long-term depression induced by sensory deprivation during cortical map plasticity in vivo. Nat Neurosci 6:291-299.

Armstrong-James M (1995) The nature and plasticity of sensory processing within adult rat barrel cortex. In: Cerebral Cortex (Jones EG, Diamond IT, eds), pp 333-373. New York, London: Plenum.

Armstrong-James M, Fox K, Das-Gupta A (1992) Flow of excitation within rat barrel cortex on striking a single vibrissa. J Neurophysiol 68:1345-1358.

Banerjee A, Meredith RM, Rodríguez-Moreno A, Mierau SB, Auberson YP, Paulsen O (2009) Double dissociation of spike timing-dependent potentiation and depression by subunit-preferring NMDA receptor antagonists in mouse barrel cortex. Cereb Cortex 19:2959-2969.

Bender KJ, Rangel J, Feldman DE (2003) Development of columnar topography in the excitatory layer 4 to layer $2 / 3$ projection in rat barrel cortex. J Neurosci 23:8759-8770.

Bender KJ, Allen CB, Bender VA, Feldman DE (2006a) Synaptic basis for whisker deprivation-induced synaptic depression in rat somatosensory cortex. J Neurosci 26:4155-4165.

Bender VA, Bender KJ, Brasier DJ, Feldman DE (2006b) Two coincidence detectors for spike timing-dependent plasticity in somatosensory cortex. J Neurosci 26:4166-4177.

Benedetti BL, Glazewski S, Barth AL (2009) Reliable and precise neuronal firing during sensory plasticity in superficial layers of primary somatosensory cortex. J Neurosci 29:11817-11827.

Brown MC, Jansen JK, Van Essen D (1976) Polyneuronal innervation of skeletal muscle in new-born rats and its elimination during maturation. J Physiol 261:387-422.

Brumberg JC, Pinto DJ, Simons DJ (1999) Cortical columnar processing in the rat whisker-to-barrel system. J Neurophysiol 82:1808-1817.

Caporale N, Dan Y (2008) Spike timing-dependent plasticity: a Hebbian learning rule. Annu Rev Neurosci 31:25-46.

Celikel T, Szostak VA, Feldman DE (2004) Modulation of spike timing by sensory deprivation during induction of cortical map plasticity. Nat Neurosci 7:534-541.

Clem RL, Celikel T, Barth AL (2008) Ongoing in vivo experience triggers synaptic metaplasticity in the neocortex. Science 319:101-104.

Dan Y, Poo MM (2006) Spike timing-dependent plasticity: from synapse to perception. Physiol Rev 86:1033-1048.

Diamond ME, Armstrong-James M, Ebner FF (1993) Experiencedependent plasticity in adult rat barrel cortex. Proc Natl Acad Sci U S A 90:2082-2086.

Esteban JA, Shi SH, Wilson C, Nuriya M, Huganir RL, Malinow R (2003) PKA phosphorylation of AMPA receptor subunits controls synaptic trafficking underlying plasticity. Nat Neurosci 6:136-143.

Fagiolini M, Fritschy JM, Löw K, Möhler H, Rudolph U, Hensch TK (2004) Specific GABAA circuits for visual cortical plasticity. Science 303:16811683.

Feldman DE (2000) Timing-based LTP and LTD at vertical inputs to layer II/III pyramidal cells in rat barrel cortex. Neuron 27:45-56.

Feldman DE (2009) Synaptic mechanisms for plasticity in neocortex. Annu Rev Neurosci 32:33-55.

Ferster D, Lindström S (1983) An intracellular analysis of geniculo-cortical connectivity in area 17 of the cat. J Physiol Lond 342:181-215.

Finnerty GT, Roberts LS, Connors BW (1999) Sensory experience modifies the short-term dynamics of neocortical synapses. Nature 400: 367-371.

Fox K (1992) A critical period for experience-dependent synaptic plasticity in rat barrel cortex. J Neurosci 12:1826-1838.

Glazewski S, Fox K (1996) Time course of experience-dependent synaptic potentiation and depression in barrel cortex of adolescent rats. J Neurophysiol 75:1714-1729.

Glazewski S, Chen CM, Silva A, Fox K (1996) Requirement for alphaCaMKII in experience-dependent plasticity of the barrel cortex. Science 272:421-423.

Glazewski S, Giese KP, Silva A, Fox K (2000) The role of alpha-CaMKII autophosphorylation in neocortical experience-dependent plasticity. Nat Neurosci 3:911-918.

Gordon JA, Stryker MP (1996) Experience-dependent plasticity of binocular responses in the primary visual cortex of the mouse. J Neurosci 16: $3274-3286$.

Hardingham N, Glazewski S, Pakhotin P, Mizuno K, Chapman PF,
Giese KP, Fox K (2003) Neocortical long-term potentiation and experience-dependent synaptic plasticity require alpha-calcium/ calmodulin-dependent protein kinase II autophosphorylation. J Neurosci 23:4428-4436.

Hayashi Y, Shi SH, Esteban JA, Piccini A, Poncer JC, Malinow R (2000) Driving AMPA receptors into synapses by LTP and CaMKII: requirement for GluR1 and PDZ domain interaction. Science 287:2262-2267.

Hensch TK (2005) Critical period plasticity in local cortical circuits. Nat Rev Neurosci 6:877-888.

Hensch TK, Fagiolini M, Mataga N, Stryker MP, Baekkeskov S, Kash SF (1998) Local GABA circuit control of experience-dependent plasticity in developing visual cortex. Science 282:1504-1508.

Ikezoe K, Tamura H, Kimura F, Fujita I (2012) Decorrelation of sensoryevoked neuronal responses in rat barrel cortex during postnatal development. Neurosci Res 73:312-320.

Ishida A, Shigeri Y, Tatsu Y, Uegaki K, Kameshita I, Okuno S, Kitani T, Yumoto N, Fujisawa H (1998) Critical amino acid residues of AIP, a highly specific inhibitory peptide of calmodulin-dependent protein kinase II. FEBS Lett 427:115-118.

Itami C, Samejima K, Nakamura S (2001) Improved data processing for optical imaging of developing neuronal connectivity in the neonatal mouse barrel cortex. Brain Res Protoc 7:103-114.

Itami C, Kimura F, Nakamura S (2007) Brain-derived neurotrophic factor regulates the maturation of layer 4 fast-spiking cells after the second postnatal week in the developing barrel cortex. J Neurosci 27: 2241-2252.

Kano M, Ohno-Shosaku T, Hashimotodani Y, Uchigashima M, Watanabe M (2009) Endocannabinoid-mediated control of synaptic transmission. Physiol Rev 89:309-380.

Kelly PT, McGuinness TL, Greengard P (1984) Evidence that the major postsynaptic density protein is a component of a $\mathrm{Ca} 2+/$ calmodulindependent protein kinase. Proc Natl Acad Sci U S A 81:945-949.

Kimura F, Nishigori A, Shirokawa T, Tsumoto T (1989) Long-term potentiation and N-methyl-D-aspartate receptors in the visual cortex of young rats. J Physiol Lond 414:125-144

Kimura F, Itami C, Ikezoe K, Tamura H, Fujita I, Yanagawa Y, Obata K, Ohshima M (2010) Fast activation of feedforward inhibitory neurons from thalamic input and its relevance to the regulation of spike sequences in the barrel cortex. J Physiol 588:2769-2787.

LaMantia AS, Rakic P (1990) Axon overproduction and elimination in the corpus callosum of the developing rhesus monkey. J Neurosci 10:21562175.

Li L, Bender KJ, Drew PJ, Jadhav SP, Sylwestrak E, Feldman DE (2009) Endocannabinoid signaling is required for development and critical period plasticity of the whisker map in somatosensory cortex. Neuron 64: 537-549.

Lichtman JW (1977) The reorganization of synaptic connexions in the rat submandibular ganglion during post-natal development. J Physiol 273: 155-177.

Lisman J, Yasuda R, Raghavachari S (2012) Mechanisms of CaMKII action in long-term potentiation. Nat Rev Neurosci 13:169-182.

Malenka RC, Bear MF (2004) LTP and LTD: an embarrassment of riches. Neuron 44:5-21.

Malinow R, Schulman H, Tsien RW (1989) Inhibition of postsynaptic PKC or CaMKII blocks induction but not expression of LTP. Science 245:862866.

Massey PV, Bashir ZI (2007) Long-term depression: multiple forms and implications for brain function. Trends Neurosci 30:176-184.

Miller SG, Kennedy MB (1985) Distinct forebrain and cerebellar isozymes of type II Ca2+/calmodulin-dependent protein kinase associate differently with the postsynaptic density fraction. J Biol Chem 260:9039-9046.

Miyazaki T, Kunii M, Tada H, Sano A, Kuroiwa Y, Goto T, Malinow R, Takahashi T (2012) Developmental AMPA receptor subunit specificity during experience-driven synaptic plasticity in the rat barrel cortex. Brain Res 1435:1-7.

Nowicka D, Soulsby S, Skangiel-Kramska J, Glazewski S (2009) Parvalbumincontaining neurons, perineuronal nets and experience-dependent plasticity in murine barrel cortex. Eur J Neurosci 30:2053-2063.

Shirokawa T, Nishigori A, Kimura F, Tsumoto T (1989) Actions of excitatory amino acid antagonists on synaptic potentials of layer II/III neurons of the cat's visual cortex. Exp Brain Res 78:489-500. 
Silva AJ, Stevens CF, Tonegawa S, Wang Y (1992) Deficient hippocampal long-term potentiation in alpha-calcium-calmodulin kinase II mutant mice. Science 257:201-206.

Simons DJ (1978) Response properties of vibrissa units in rat SI somatosensory neocortex. J Neurophysiol 41:798-820.

Sjöström PJ, Turrigiano GG, Nelson SB (2003) Neocortical LTD via coincident activation of presynaptic NMDA and cannabinoid receptors. Neuron 39:641-654.

Stern EA, Maravall M, Svoboda K (2001) Rapid development and plasticity of layer 2/3 maps in rat barrel cortex in vivo. Neuron 31:305-315.

Sugiura H, Yamauchi T (1992) Developmental changes in the levels of $\mathrm{Ca} 2+/$ calmodulin-dependent protein kinase II alpha and beta proteins in soluble and particulate fractions of the rat brain. Brain Res 593:97-104.
Takahashi T, Svoboda K, Malinow R (2003) Experience strengthening transmission by driving AMPA receptors into synapses. Science 299:1585-1588.

Wen JA, Barth AL (2011) Input-specific critical periods for experiencedependent plasticity in layer $2 / 3$ pyramidal neurons. J Neurosci 31:4456-4465.

Wiesel TN, Hubel DH (1963) Single-cell responses in striate cortex of kittens deprived of vision in one eye. J Neurophysiol 26:1003-1017.

Yasuda H, Barth AL, Stellwagen D, Malenka RC (2003) A developmental switch in the signaling cascades for LTP induction. Nat Neurosci 6:15-16.

Zhu JJ, Esteban JA, Hayashi Y, Malinow R (2000) Postnatal synaptic potentiation: delivery of GluR4-containing AMPA receptors by spontaneous activity. Nat Neurosci 3:1098-1106. 